Thorax (1966), $21,57$.

\title{
Effects of opiates in chronic bronchitis
}

\author{
W. D. MURRAY AND I. W. B. GRANT \\ From the Respiratory Diseases Unit, Northern General Hospital, \\ and the Department of Respiratory Diseases, University of Edinburgh
}

It has been standard teaching for many years that opiates should not in any circumstances be given to dyspnoeic patients with chronic bronchitis, but the evidence on which this view is based is derived almost solely from clinical impressions. Although morphine and its derivatives have been shown to diminish the ventilatory response to carbon dioxide in normal human volunteers (Loeschcke, Sweel, Kough, and Lambertsen, 1953), there have been virtually no scientifically controlled observations on the effect of opiates in patients with ventilatory failure complicating chronic bronchitis and emphysema.

Attempts have been made in such patients to study retrospectively the effect of opiates on respiration by observing the changes which occur in minute volume and in the carbon dioxide tension, oxygen saturation, and $p \mathrm{H}$ of arterial blood during recovery from injections of morphine. In one such study on five patients with severe emphysema (Wilson, Hoseth, and Dempsey, 1954) these measurements were made 'during narcosis' after the injection of $15 \mathrm{mg}$. morphine, and 'on recovery'. Since the morphine had been administered (on incorrect indications) before the patients were admitted to hospital in ventilatory failure, and no precise time relationships are given, it cannot be assumed that the severe hypercapnia, hypoxaemia, and respiratory acidosis which were found on analysis of arterial blood samples taken 'during narcosis' were solely due to the central action of morphine on respiration, since they may have been partly or even mainly due to secondary effects such as bronchial obstruction by secretions.

The authors based their conclusion that morphine caused central depression of respiration on the observation that the figures for arterial carbon dioxide tension, $p \mathbf{H}$, and oxygen saturation and for respiratory minute volume improved significantly 'on recovery from sedation'. This conclusion seems to be inadmissible because the time interval between the withdrawal of the two arterial samples was not stated, and because precise details of the treatment the patients had received during this period were not given. Even a few effective coughs could, by clearing the airways, have produced a marked reduction in the degree of hypercapnia and hypoxaemia, and the administration of respiratory stimulants, which, according to the text, some patients may have received, would totally invalidate the results of the investigation.

Our interest in the subject was aroused by the difficulty we experienced in relieving intense dyspnoea in patients with chronic bronchitis and emphysema who had reached the terminal stages of chronic ventilatory failure. In one particular patient, whose respiratory distress was such that he repeatedly expressed a desire to die, we considered it would be justifiable to give an opiate as a last resort, and we observed the effect of the drug on the arterial blood gas status. The arterial oxygen saturation $\left(\mathrm{SaO}_{2}\right)$, estimated on each occasion while the patient was breathing oxygen from a Venturi mask at the $25 \%$ gauge setting, had for several weeks fluctuated between $75 \%$ and $85 \%$, and the arterial carbon dioxide tension $\left(\mathrm{PaCO}_{2}\right)$ had varied between $90 \mathrm{~mm}$. $\mathrm{Hg}$ and $100 \mathrm{~mm}$. $\mathrm{Hg}$, but the arterial $p \mathrm{H}$ had remained within the normal range. It was decided to give him in the first instance a very small dose of opiate (papaveretum, $10 \mathrm{mg}$. subcutaneously), and to increase the dose only if this did not produce any alarming change in his clinical state or in his arterial blood gas status. The patient claimed that after the injection he was able to breathe more comfortably, and his respiratory efforts seemed less laboured. This effect was augmented when he was given $20 \mathrm{mg}$. papaveretum on two subsequent occasions, but he became relaxed and slightly drowsy with the higher dose.

Samples of arterial blood were withdrawn immediately before each injection and again 90 minutes later. The figures obtained for $\mathrm{PaCO}_{2}$, 


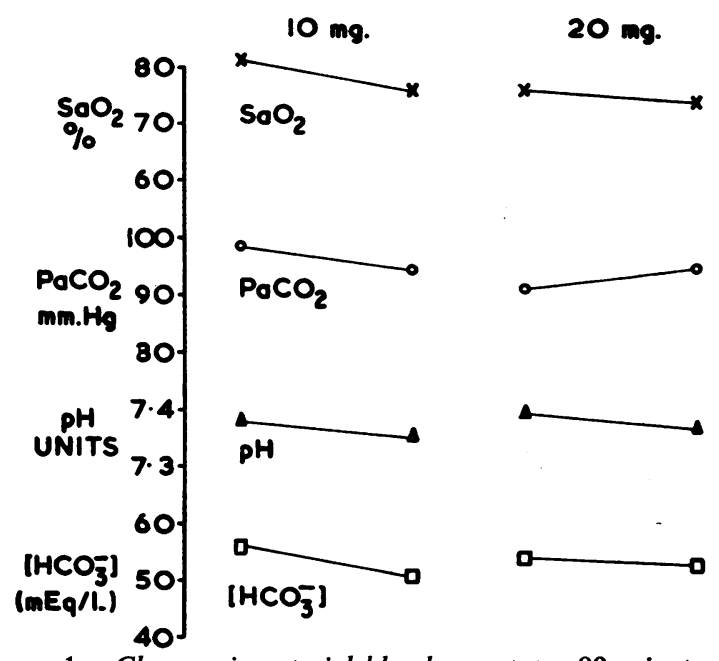

FIG. 1. Changes in arterial blood gas status 90 minutes after subcutaneous injections of papaveretum.

$p \mathrm{H}$, and $\mathrm{SaO}_{2}$ from these samples are shown in Figure 1. With the smaller dose $(10 \mathrm{mg}$.) of papaveretum there was virtually no change in any of these measurements. With the larger dose (20 mg.) the $\mathrm{SaO}_{2}$ fell on both occasions, but not to an alarming degree, while the $\mathrm{PaCO}_{2}$ fell slightly on the first occasion and rose slightly on the second. Although there was a slight fall in $p H$ on both occasions, the figures remained within the accepted range of normal.

Following this demonstration that $20 \mathrm{mg}$. of papaveretum had no seriously detrimental effects, even in a patient with a $\mathrm{PaCO}_{2}$ of almost $100 \mathrm{~mm}$. $\mathrm{Hg}$, we tried to determine more precisely the physiological changes produced by this drug in patients with chronic bronchitis and emphysema with and without ventilatory failure.

Owing to the lack of scientific data on the response of such patients to opiates, it was difficult to decide whether or not a particular patient could safely be included in the study. All those with any significant degree of reversible airways obstruction were excluded for two reasons: (1) because we suspected that the response to papaveretum in these patients might not be the same as in patients without reversible airways obstruction, and (2) because we thought that the administration of opiates to patients exhibiting overt asthmatic features might involve some degree of risk. We also excluded from the study patients who were either suffering from acute exacerbations of bronchitis (in most cases caused by infection) or who had recently recovered from such an episode. Safety was the main reason for this rejection, since we thought that opiates were potentially? more dangerous in these circumstances, possiblye because of their action in depressing the cough reflex. We also considered that the presence of excessive secretions in the bronchi might cause transient interference with the ventilation of porn tions of lung and produce changes in the arterial blood gases which were not directly related to the central effects of papaveretum.

As a result of these exclusions the study was confined to those in a relatively stable state as far as their arterial blood gases were concerned, buiv the actual degree of ventilatory failure, as judged_ by the level of $\mathrm{SaO}_{2}$ and $\mathrm{PaCO}_{2}$, did not influenceir the selection. In order to increase the number of subjects with normal arterial blood gases we included bronchitic patients who were being given $\vec{C}$ papaveretum as premedication for bronchoscopy the studies being completed before the introduc $\frac{-}{2}$ tion of the bronchoscope. Some of these patients? were given scopolamine $(0.4 \mathrm{mg}$.) together with $\overrightarrow{0}$ papaveretum $(20 \mathrm{mg}$.), and this small group was analysed separately.

\section{DETAILS OF PATIENTS STUDIED}

Twenty-two patients given papaveretum alone were气 investigated, all with typical features of the chronice bronchitis/emphysema syndrome ranging in clinical $F_{\bar{\sigma}}$ severity from mild to very severe. There were 19 men and three women, and all were over the age of 405 years. None had any other pathological condition in the bronchi or lungs or any evidence of respiratory infection, e.g., pus in the sputum, either at the time of the study or in the fortnight preceding it. A significant degree of reversible airways obstruction had. been excluded in all patients by the estimation of forced expiratory volume $(1 \mathrm{sec}$.) before and after $\mathrm{a}$. subcutaneous injection of adrenaline and an inhalation of isoprenaline.

Of the 22 patients, 20 were studied on one occasiono only, and two on two separate occasions some days apart, making a total of 24 studies available foro analysis. Three additional patients were observed afterthe injection of papaveretum and scopolamine.

\section{METHOD}

With the patient resting comfortably in bed, a Rileyo needle was inserted into the brachial artery and of sample of blood was withdrawn. Papaveretum, $20 \mathrm{mg}$., was then injected subcutaneously. The Riley needles? was left in situ for 60 minutes, when a second blood sample was withdrawn. Before the insertion of the $\bar{\sigma}$ arterial needle the minute volume of pulmonary ventilation ( $\left.\dot{V}_{E}\right)$ was measured, using a tightly fitting face-piece connected to a Drager Volumeter. The figure used for analysis was the average of three too five readings taken after equilibrium had been estab- 
lished. An interval of five minutes was allowed to elapse between the removal of the face-piece and the withdrawal of the first arterial sample. Exactly the same procedure was repeated before the second sample was taken. In three of the studies the minute volume was not measured because the patients were unable to tolerate the face-piece. Complete data for $\dot{V} E$ were thus obtained in 21 of the 24 studies with papaveretum alone in addition to all three of the studies with papaveretum and scopolamine.

In all but two of the studies, to which reference will later be made, the patients were breathing air throughout the period of observation.

The samples of arterial blood were examined by the following techniques within a few minutes of withdrawal :

ARTERIAL OXYGEN SATURATION Measured by means of a Kipp Brinkman Haemoreflector (Zijlstra, 1953).

ARTERIAL CARBON DIOXIDE TENSION Measured by means of a Severinghaus $\mathrm{PCO}_{2}$ electrode (Severinghaus and Bradley, 1958), the readings being made on an E.I.L. Vibron electrometer (Model 33B) and $p H$ measuring unit (Model C33B).

ARTERIAL $p H$ Measured by means of an E.I.L. replaceable capillary electrode model SHH 33, the readings being made on an E.I.L. Vibron electrometer (Model 33B) and $p \mathrm{H}$ measuring unit (Model C33B).

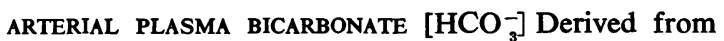
arterial carbon dioxide tension and arterial $p H$, using a $\mathrm{PCO}_{2} /$ bicarbonate diagram (Campbell, 1962).

\section{RESULTS}

Table I summarizes the results obtained from arterial blood gas analysis and minute volume estimations before the injection of papaveretum.

\section{T A B LE I}

ARTERIAL BLOOD GAS STATUS AND PULMONARY VENTILATION BEFORE INJECTION OF PAPAVERETUM (24 STUDIES)

\begin{tabular}{|c|c|c|c|c|c|c|}
\hline & \multicolumn{6}{|c|}{ No. of Studies } \\
\hline & & 8 & \multicolumn{2}{|r|}{11} & \multicolumn{2}{|r|}{5} \\
\hline & \multicolumn{2}{|c|}{$\begin{array}{c}\mathrm{PaCO}_{2} \\
<47 \mathrm{~mm} . \mathrm{Hg}\end{array}$} & \multicolumn{2}{|c|}{$\begin{array}{c}\mathrm{PaCO}_{2} \\
47 \text { to } 60 \mathrm{~mm} . \mathrm{Hg}\end{array}$} & \multicolumn{2}{|c|}{$\underset{>}{\mathrm{PaCO}_{2}}$} \\
\hline & Mean & Range & Mean & Range & Mean & Range \\
\hline 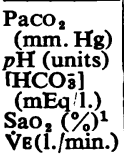 & $\begin{array}{c}42 \cdot 3 \\
7.42 \\
\\
26 \cdot 9 \\
90 \cdot 4 \\
8 \cdot 5\end{array}$ & \begin{tabular}{|c|}
$34-47$ \\
$7 \cdot 38-7 \cdot 45$ \\
$24-31$ \\
$83-97$ \\
$3 \cdot 1-14 \cdot 7$
\end{tabular} & $\begin{array}{c}55 \cdot 0 \\
7 \cdot 38 \\
31 \cdot 7 \\
85 \cdot 12 \\
7 \cdot 3\end{array}$ & $\begin{array}{c}49-60 \\
7 \cdot 27-7 \cdot 43 \\
\\
27-38 \\
75-93 \\
3 \cdot 6-15 \cdot 8\end{array}$ & $\begin{array}{c}78 \cdot 9 \\
7 \cdot 39 \\
45 \cdot 4 \\
76 \cdot 5^{3} \\
8 \cdot 1^{3}\end{array}$ & $\begin{array}{c}61-98 \\
7 \cdot 36-7 \cdot 40 \\
37-56 \\
74-78 \\
7 \cdot 0-9 \cdot 7\end{array}$ \\
\hline
\end{tabular}

1 Patients receiving oxygen not included.

2 Nine patients only.

8 Three patients only.
The figures are grouped according to whether the $\mathrm{PaCO}_{2}$ was normal, slightly or moderately raised (47 to $60 \mathrm{~mm}$. $\mathrm{Hg}$ ), or greatly increased (above $60 \mathrm{~mm}$. $\mathrm{Hg}$ ). In most of the patients with a normal $\mathrm{PaCO}_{2}$ the $\mathrm{SaO}_{2}$ was above $90 \%$, and in most of those with a $\mathrm{PaCO}_{2}$ of between 47 and 60 $\mathrm{mm}$. $\mathrm{Hg}$ it was between 80 and $90 \%$. Two of the patients with a $\mathrm{PaCO}_{2}$ of more than $60 \mathrm{~mm}$. $\mathrm{Hg}$ were so severely hypoxaemic that they had to be given oxygen throughout the period of observation, and the figures obtained for $\mathrm{SaO}_{2}$ were not included in this analysis. The mean figure of $76.5 \%$ for the remaining three patients is therefore likety to underestimate the degree of hypoxaemia in the group as a whole.

The mean values for arterial $p \mathrm{H}$ were normal in all the $\mathrm{PaCO}_{2}$ groupings: indeed a figure of below 7.36 units was recorded in only two of the 24 studies. In all but two of the patients with a raised $\mathrm{PaCO}_{2}$ the respiratory acidosis was fully compensated by an increase in plasma bicarbonate which, as would be expected, was greatest in those with the highest figures for $\mathrm{PaCO}_{2}$.

There was a very wide variation in the figures obtained for $\dot{V} E$, but neither in individuals nor in the $\mathrm{PaCO}_{2}$ groupings was the level of pulmonary ventilation related, inversely or otherwise, to the $\mathrm{PaCO}_{2}$. Figures as high as $121 . / \mathrm{min}$. were recorded both in patients with a normal $\mathrm{PaCO}_{2}$ and in those with severe hypercapnia, and very low figures such as $31 . / \mathrm{min}$. were also recorded in both groups. The minute volume of pulmonary ventilation depends not only on the metabolic activity of the patient and the size of the anatomical dead space but also on the ventilation : blood flow ratios within the lungs, which may be grossly disturbed in advanced chronic respiratory disease. The wide range of figures obtained for VE in this series is therefore not remarkable, but with the method used a considerable experimental error is probably inevitable (Byles, 1960). The absolute figures for $\dot{V} E$ obtained in this study must therefore be accepted with reserve, but serial recordings of $\dot{V} E$ in individual patients probably provide a fairly reliable index of changes in the level of pulmonary ventilation.

The procedure by which an interval of 5 minutes was allowed to elapse after the measurement of $\dot{V} E$ before each sample of arterial blood was withdrawn is open to criticism on the grounds that the level of pulmonary ventilation might have altered during this period. It was considered, however, that the disturbance of breathing liable to be provoked by the measurement of pulmonary ventilation might alter blood gas tensions if $\hat{V E}$ 
were recorded immediately before or during arterial sampling. Conversely, the painful stimuli which arterial puncture may produce might have stimulated respiration and thus invalidated certain of the recordings of $\dot{V} E$ if it had been performed immediately before or during the measurement of pulmonary ventilation. The procedure finally adopted was a form of compromise, the interval of 5 minutes being regarded as sufficient to allow breathing to return to 'normal' after the measurement of $\dot{V} E$ had been completed.

In two of the three patients given papaveretum plus scopolamine the initial $\mathrm{PaCO}_{2}, p \mathrm{H}$, and $\mathrm{SaO}_{2}$ were all normal, while in the third the $\mathrm{PaCO}_{2}$ was $46 \mathrm{~mm}$. $\mathrm{Hg}$ and the $\mathrm{SaO}_{2} 90 \%$. VE ranged from 6.9 to $11 \cdot 11 . / \mathrm{min}$.

EFFECTS OF PAPAVERETUM The changes in the various measurements 60 minutes after the injection of papaveretum are shown in Tables II and III, and figures from a typical patient are plotted in Figure 2. In Table II the results are given for

T A B LE I I

MEAN CHANGES IN ARTERIAL BLOOD GAS STATUS AND PULMONARY VENTILATION 60 MINUTES AFTER INJECTION OF 20 MG. PAPAVERETUM (24 STUDIES)

\begin{tabular}{|c|c|c|c|c|c|}
\hline & & $\begin{array}{c}\text { Before } \\
\text { Injec- } \\
\text { tion }\end{array}$ & $\begin{array}{c}\text { After } \\
\text { Injec- } \\
\text { tion }\end{array}$ & $\begin{array}{c}\text { Dif- } \\
\text { ference }\end{array}$ & $\begin{array}{l}\text { Value of } P \\
\text { if }<0.05\end{array}$ \\
\hline $\begin{array}{l}\mathrm{PaCO}_{2}(\mathrm{~mm} . \mathrm{Hg}) \\
\text { pH (units) } \\
{[\mathrm{HCO}-] \text { (mEq/l.) }} \\
\mathrm{SaO}_{2}(\%) \\
\operatorname{VE}(1 . / \mathrm{min} .)\end{array}$ & .. & $\begin{array}{c}55 \cdot 7 \\
7.40 \\
33.0 \\
85.3 \\
6.9\end{array}$ & $\begin{array}{c}57 \cdot 4 \\
7 \cdot 38 \\
33 \cdot 0 \\
81 \cdot 4 \\
5 \cdot 1\end{array}$ & $\begin{array}{l}+1 \cdot 7 \\
-0.02 \\
0 \\
-3.9 \\
-1.8\end{array}$ & $\begin{array}{l}0.05>P>0.02 \\
0005>P>0.001 \\
0.001>P \\
0.001>P\end{array}$ \\
\hline
\end{tabular}

T A BLE III

MEAN CHANGES IN ARTERIAL BLOOD GAS STATUS AND MINUTE VOLUME OF PULMONARY VENTILATION 60 MINUTES AFTER INJECTION OF 20 MG. PAPAVERETUM: ANALYSIS OF RESULTS ACCORDING TO LEVEL OF $\mathrm{PaCO}_{2}$

\begin{tabular}{|c|c|c|c|c|}
\hline & $\begin{array}{c}\text { Before } \\
\text { Injec- } \\
\text { tion }\end{array}$ & $\begin{array}{c}\text { After } \\
\text { Injec- } \\
\text { tion }\end{array}$ & $\begin{array}{c}\text { Dif- } \\
\text { ference }\end{array}$ & $\begin{array}{l}\text { Value of } \mathbf{P} \\
\text { if }<0.05\end{array}$ \\
\hline $\left.\begin{array}{c}\mathrm{PaCO}_{2}<47 \mathrm{~mm} . \mathrm{Hg}(8 \\
\mathrm{PaCO}_{2}(\mathrm{~mm} . \mathrm{Hg})\end{array}\right]$ & $\begin{array}{l}\text { studies': } \\
42 \cdot 3 \\
7 \cdot 42 \\
26.9 \\
90 \cdot 4 \\
8.5\end{array}$ & $\begin{array}{c}43 \cdot 8 \\
7 \cdot 40 \\
26 \cdot 5 \\
87.7 \\
6 \cdot 7\end{array}$ & $\begin{array}{l}+1.5 \\
-0.02 \\
-0.4 \\
-2.7 \\
-1.8\end{array}$ & $\begin{array}{c}0.05>\bar{P}>0.02 \\
\overline{\bar{Z}} \\
0.05>0.02\end{array}$ \\
\hline 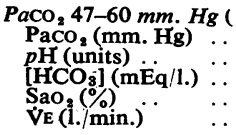 & $\mid$\begin{tabular}{|l}
1 studies \\
$55 \cdot 0$ \\
$7 \cdot 38$ \\
$31 \cdot 7$ \\
$85 \cdot 2$ \\
$7 \cdot 3$
\end{tabular} & $\begin{array}{l}57 \cdot 8 \\
7 \cdot 37 \\
33 \cdot 2 \\
81 \cdot 2 \\
5 \cdot 2\end{array}$ & $\begin{array}{l}+2 \cdot 8 \\
-0.01 \\
+1.5 \\
-4 \cdot 0 \\
-2 \cdot 1\end{array}$ & $\begin{array}{c}\bar{Z} \\
\begin{array}{c}0.01>\mathbf{P}>0.005 \\
0.001>P\end{array}\end{array}$ \\
\hline 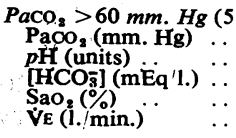 & $\begin{array}{l}\text { studies): } \\
78 \cdot 9 \\
7.39 \\
45.4 \\
77.5 \\
8 \cdot 1\end{array}$ & $\begin{array}{c}78 \cdot 7 \\
7 \cdot 37 \\
43 \cdot 0 \\
71 \cdot 7 \\
7 \cdot 1\end{array}$ & $\begin{array}{l}-0.2 \\
-0.02 \\
-2 \cdot 4 \\
-5.8 \\
-1 \cdot 0\end{array}$ & $\begin{array}{c}\bar{Z} \\
0.02>\mathbf{p}>0.01\end{array}$ \\
\hline
\end{tabular}

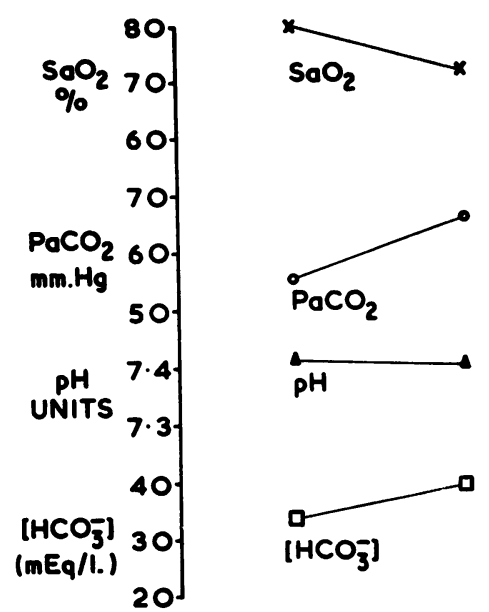

FIG. 2. Changes in arterial blood gas status 60 minutes after subcutaneous injection of papaveretum $(20 \mathrm{mg}$.).

the whole series of 24 studies. There was a mean increase of $1.7 \mathrm{~mm} . \mathrm{Hg}$ in $\mathrm{PaCO}_{2}$, a mean reduction of 0.02 unit in $p \mathrm{H}$, a mean reduction of $3.9 \%$ in $\mathrm{SaO}_{2}$, and a mean reduction of $1.81 . / \bar{\partial}$ min. in $\dot{V} E$. The change in $\mathrm{PaCO}_{2}$ was significant at the $5 \%$ level, and the degree of significance was $\mathbb{Q}$ even higher in respect of changes in $p H(P<0.005), \stackrel{2}{\Rightarrow}$ $\mathrm{SaO}_{2}(\mathrm{P}<0.001)$, and $\dot{\mathrm{V}}(\mathrm{P}<0.001)$. No change $\frac{\mathrm{O}}{3}$ was recorded in plasma [HCO-].

In Table III, which subdivides the results according to the initial level of $\mathrm{PaCO}_{2}$, the changes in $\mathrm{PaCO}_{2}$ do not achieve statistical significance at the $5 \%$ level in any of the groups, and those in $p \mathrm{H}$ reach this level of significance only in the group of patients with normocapnia $\left(\mathrm{PaCO}_{2}<473\right.$ $\mathrm{mm}$. $\mathbf{H g}$ ). The reduction in $\mathrm{SaO}_{2}$ is statistically significant at the $1 \%$ level in patients with moderate hypercapnia $\left(\mathrm{PaCO}_{2} 47 \text { to } 60 \mathrm{~mm} \text {. } \mathrm{Hg}\right)_{0}$ and at the $2 \%$ level in those with severe hypercapnia $\left(\mathrm{PaCO}_{2}>60 \mathrm{~mm}\right.$. $\left.\mathrm{Hg}\right)$, and it almosto achieves significance at the $5 \%$ level in those with normocapnia. The reduction in $\dot{V} E$ is statisticallyo significant $(P<0.05)$ in the normocapnic patients and highly significant $(P<0.001)$ in the patients N with moderate hypercapnia. As it was not possible $\omega_{\sigma}^{\omega}$ to measure the minute volume of pulmonary ventilation in two of the five patients with severe hypercapnia because of dyspnoea, there is nos reliable information about changes in $\dot{V E}$ in this group.

An increase in $\mathrm{PaCO}_{2}$ was recorded in 14 of the 24 studies, and a reduction in $p \mathrm{H}$ in 18 . A reduc- $\frac{\overrightarrow{\mathrm{d}}}{\mathrm{O}}$ tion in $\mathrm{SaO}_{2}$ was recorded in 20 of the 24 studies, and in 13 it exceeded $5 \%$. A reduction in VE was 
recorded in 18 of the 21 studies in which this parameter was measured. Considering only the 16 patients with hypercapnia $\left(\mathrm{PaCO}_{2}>47 \mathrm{~mm}\right.$. $\left.\mathrm{Hg}\right)$, the $\mathrm{PaCO}_{2}$ increased in 10 studies, the $p \mathrm{H}$ decreased in 12, and the $\mathrm{SaO}_{2}$ decreased in 14 . There was a reduction in $\dot{V E}^{2}$ in 13 of the 14 studies in which this parameter was measured.

The degree of change in $\mathrm{PaCO}_{2}, p \mathrm{H}$, and $\dot{\mathrm{VE}}$ was apparently not related to the initial level of $\mathrm{PaCO}_{2}$, but the mean reduction in $\mathrm{SaO}_{2}$ was more than twice as great in patients with severe hypercapnia $(5.8 \%)$ as it was in those with normocapnia $(2.7 \%)$. The degree of reduction in $\mathrm{SaO}_{2}$ in patients with moderate hypercapnia $(4 \%)$ was intermediate between the figures for the other two groups. The largest single increase in $\mathrm{PaCO}_{2}$ was $11 \mathrm{~mm}$. $\mathrm{Hg}$, and the largest single decreases in $p \mathrm{H}, \mathrm{SaO}_{2}$, and $\mathrm{VE}$ were 0.05 unit, $11 \%$, and $4.7 \mathrm{l}$./ min. respectively.

In all 14 studies in which an increase in $\mathrm{PaCO}_{2}$ was observed, there was a slight fall in arterial $p \mathrm{H}$. As these two measurements were made by independent techniques, it can be assumed that valid trends were being observed and that retention of carbon dioxide was associated with incompletely compensated respiratory acidosis. Although there was no change in the mean level of plasma $\left[\mathrm{HCO}_{\overline{3}}\right]$ in this series, the plasma $\left[\mathrm{HCO}_{\overline{3}}\right]$ increased in all six patients in whom a rise of more than $4 \mathrm{~mm}$. $\mathrm{Hg}$ in $\mathrm{PaCO}_{2}$ was recorded, but in only one of the eight patients with a smaller rise.

EFFECTS OF PAPAVERETUM PLUS SCOPOLAMINE The effects of the injection of papaveretum plus scopolamine are shown in Table IV. In all three patients

TABLE IV

MEAN CHANGES IN ARTERIAL BLOOD GAS STATUS 60 MINUTES AFTER INJECTION OF 20 MG. PAPAVERETUM PLUS 0.4 MG. SCOPOLAMINE (3 STUDIES)

\begin{tabular}{|c|c|c|c|c|c|}
\hline & & & & $\begin{array}{c}\text { Before } \\
\text { Injection }\end{array}$ & $\begin{array}{c}60 \text { Minutes } \\
\text { After Injection }\end{array}$ \\
\hline 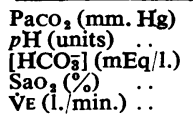 & $\begin{array}{l}. \\
\therefore \\
\therefore \\
\cdots\end{array}$ & $\begin{array}{l}\cdots \\
\cdots \\
\cdots \\
\cdots\end{array}$ & $\begin{array}{l}\ldots \\
\cdots \\
\cdots \\
\cdots\end{array}$ & $\begin{array}{l}41 \cdot 0 \\
7 \cdot 40 \\
24 \cdot 5 \\
94 \cdot 0 \\
8 \cdot 9\end{array}$ & $\begin{array}{c}44 \cdot 5 \\
7 \cdot 40 \\
27 \cdot 7 \\
90 \cdot 3 \\
4 \cdot 3\end{array}$ \\
\hline
\end{tabular}

there was a reduction in $\dot{V} E$ considerably greater than that recorded in patients given papaveretum alone. In two it exceeded $51 . / \mathrm{min}$. and in the other it was almost $3 \mathrm{l} / \mathrm{min}$. In two of the three patients the $\mathrm{PaCO}_{2}$ rose by $4 \mathrm{~mm}$. $\mathrm{Hg}$ and $7 \mathrm{~mm}$. $\mathrm{Hg}$, while in the third (somewhat unexpectedly) it did not alter. The $\mathrm{SaO}_{2}$ fell by $3 \%$ in one and by $4 \%$ in each of the other two
SUBJECTIVE EFFECTS The subjective effects of papaveretum were the same as those experienced by normal individuals. In addition about half of the dyspnoeic patients said that they could breathe more easily. Some became drowsy, but this feature was no more evident in grossly hypercapnic patients than in those with a normal $\mathrm{PaCO}_{2}$. Those patients who had been given scopolamine in addition to papaveretum were much more drowsy than the others. No delayed ill effects from the papaveretum injections were recognized.

\section{DISCUSSION}

On the assumption that papaveretum is a respiratory depressant, the drug would be expected to reduce the minute volume of pulmonary ventilation. The effect of this would be to produce a fall in $\mathrm{SaO}_{2}$ and a rise in $\mathrm{PaCO}_{2}$. The latter would in turn tend to reduce the arterial $p \mathrm{H}$, but the actual change in $p \mathrm{H}$ would be dependent on the rate of increase in plasma $\left[\mathrm{HCO}_{\overline{3}}\right]$. This investigation has to a large extent produced the results anticipated. An analysis of the series as a whole provides indisputable evidence that an injection of $20 \mathrm{mg}$. of papaveretum causes an increase in $\mathrm{PaCO}_{2}$ and reductions in $p \mathrm{H}, \mathrm{SaO}_{2}$, and $\dot{\mathrm{VE}}$, whereas the plasma $\left[\mathrm{HCO}_{\overline{3}}\right]$ remains unchanged after one hour, presumably because retention of bicarbonate by the kidneys has not had time to occur.

It is clear, both on statistical grounds and from a study of individual patients, that there is a difference in magnitude between the effect of decreased pulmonary ventilation on $\mathrm{PaCO}_{2}$ and its effect on $\mathrm{SaO}_{2}$. In the series as a whole, the reduction in $\mathrm{SaO}_{2}$ achieves a higher degree of statistical significance than the increase in $\mathrm{PaCO}_{2}$. Furthermore, when the results are analysed according to the initial level of $\mathrm{PaCO}_{2}$, by which the patients are separated into groups with normocapnia, moderate hypercapnia, and severe hypercapnia, the increase in $\mathrm{PaCO}_{2}$ is not statistically significant at the $5 \%$ level in any group, whereas the reduction in $\mathrm{SaO}_{2}$ is highly significant in the groups with moderate hypercapnia $(P<0.01)$ and severe hypercapnia $(\mathrm{P}<0.02)$ and almost significant at the $5 \%$ level in the normocapnic group. An analysis of the response of individual patients in this series shows that the $\mathrm{PaCO}_{2}$ increased in only $58 \%$, whereas the $\mathrm{SaO}_{2}$ decreased in $75 \%$. If only hypercapnic patients are considered, the figures are $62 \%$ and $87 \%$ respectively. The differing relation between $\mathrm{SaO}_{2}$ and $\mathrm{VE}$ on the one hand, and between $\mathrm{PaCO}_{2}$ and $\dot{\mathrm{V} E}$ on the other, is shown in Fig. 3, where it can be seen that a reduction in $\dot{V E}_{E}$ was associated with a fall in 


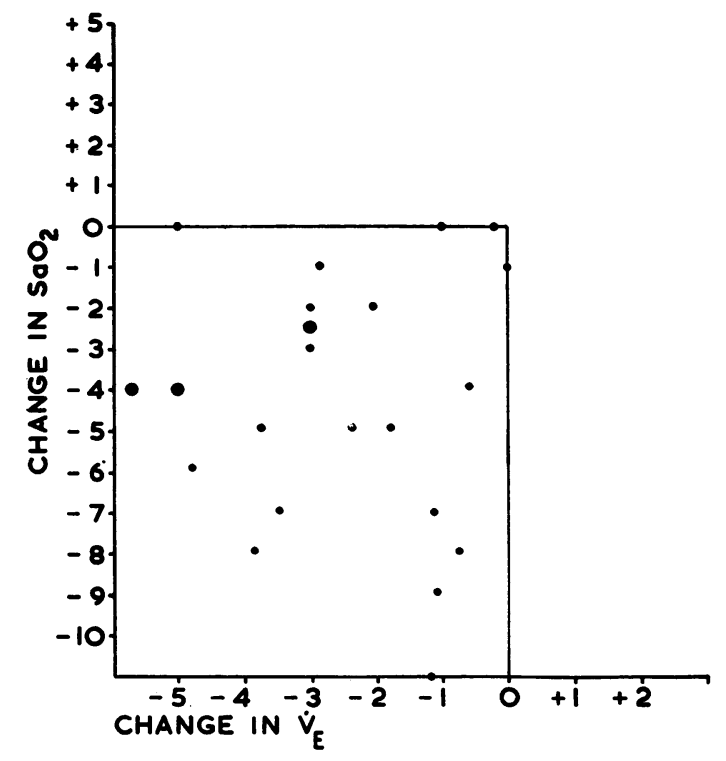

(a)

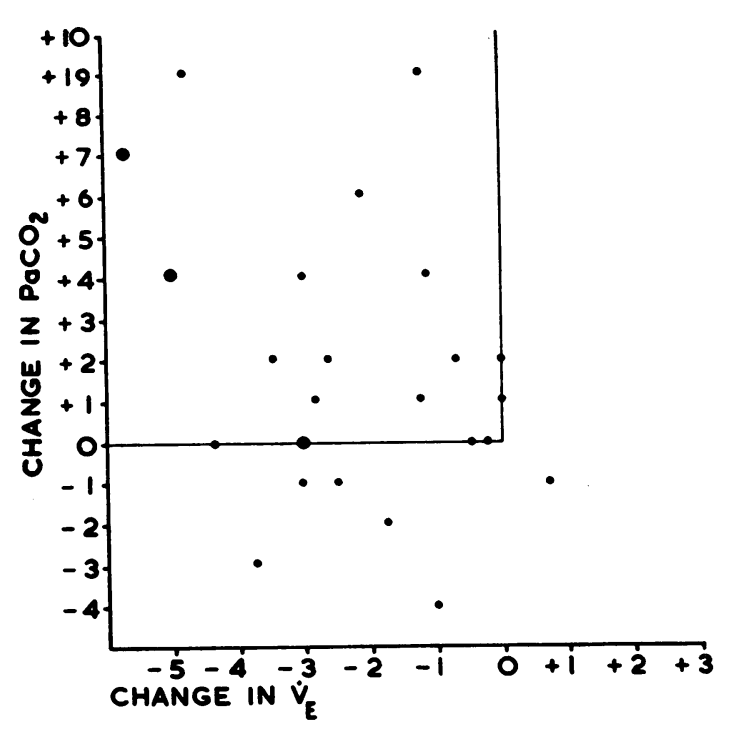

(b)

FIG. 3. Relation of changes in $\dot{\mathrm{V}} \mathrm{E}$ (a) to changes in $\mathrm{SaO}_{2}$ and (b) to changes in $\mathrm{PaCO}_{2}$, after the subcutaneous injection of papaveretum $(20 \mathrm{mg}$.). The larger points indicate patients given papaveretum $(20 \mathrm{mg}$.) plus scopolamine (0.4 mg.).

$\mathrm{SaO}_{2}$ in 15 of the 21 studies in which both measurements were recorded, but with a rise in $\mathrm{PaCO}_{2}$ in only 10 studies.

In chronic ventilatory failure the hypoxaemia may not be associated with a commensurate increase in $\mathrm{PaCO}_{2}$. The usual explanation for this is that the hypoxaemia is produced by a disturbance of the relation between ventilation and blood flow in individual alveoli or groups of alveoli, and that hyperventilation of normally functioning alveoli in response to the stimuli of hypercapnia and hypoxia prevents any great increase in $\mathrm{PaCO}_{2}$ but cannot correct to any significant degree the reduction in $\mathrm{SaO}_{2}$. The results of this investigation suggest that the administration of an opiate to patients with chronic bronchitis not only reduces total alveolar ventilation but also, and to a relatively greater degree, reduces the alveolar ventilation:blood flow ratio. It is possible that a reduction in the total alveolar ventilation may cause a differential reduction in the ventilation of certain groups of alveoli and in that way reduce the overall ventilation:blood flow ratio to a degree proportionately in excess of the reduction in total alveolar ventilation. On the other hand, reduction in the ventilation : blood flow ratio might be caused by increased perfusion of under- ventilated alveoli, resulting from the direct action of papaveretum on the pulmonary vasculature. Provided any reduction in the ventilation:blood flow ratio produced in either of these ways is not completely offset by a proportionate reduction in total alveolar ventilation, the outcome will be a fall in $\mathrm{SaO}_{2}$ associated with a proportionately smaller rise in $\mathrm{PaCO}_{2}$ or, in some cases, no rise at all.

These theories are highly speculative, and there may be other more acceptable explanations for this phenomenon. Nevertheless, it seems likely that the effect of opiates on respiration involves processes much more complex than a simple reduction in pulmonary ventilation caused by depression either of the intrinsic activity of the respiratory centre or of its sensitivity to changes in arterial blood gas tensions. To elucidate these processes is a formidable task which will involve, in addition to the measurement of arterial blood gas tensions, the estimation of ventilation: blood flow ratios, 'transfer factor', pulmonary blood flow, and pulmonary vascular resistance before and after administration of the drug.

The rise in $\mathrm{PaCO}_{2}$ after the injection of papaveretum, except in a few cases, was relatively slight, and the resulting degree of respiratory 
acidosis was correspondingly trivial. There was no mean increase in plasma $\left[\mathrm{HCO}_{\overline{3}}\right]$ in the series as a whole, presumably because the interval between the time at which the $\mathrm{PaCO}_{2}$ began to increase and the withdrawal of the second arterial sample was usually too short to allow the kidneys to retain sufficient bicarbonate to alter its level in the plasma. It appeared, however, that if the $\mathrm{PaCO}_{2}$ rose by more than $4 \mathrm{~mm}$. $\mathrm{Hg}$, the plasma [ $\mathrm{HCO}_{-3}^{-}$had increased by the time the second sample was taken.

As has already been shown, the effect of papaveretum on $\mathrm{SaO}_{2}$ was both more consistent and more severe than its effect on $\mathrm{PaCO}_{2}$. In 13 of the 20 studies in which a fall in $\mathrm{SaO}_{2}$ was recorded it exceeded $5 \%$ and in one it was as much as $11 \%$. Although none of these patients appeared to suffer any immediate ill effects, perhaps because they were under constant supervision, increases of this magnitude in the degree of hypoxaemia in patients with chronic ventilatory failure must be undesirable and potentially dangerous. The risk seems to be greatest in patients with severe degrees of ventilatory failure, as in this investigation such patients not only had a lower initial $\mathrm{SaO}_{2}$ but also showed a greater reduction in this measurement after papaveretum had been given. Furthermore, the antitussive effects of opiates may impair expectoration and, by causing bronchial obstruction and reducing pulmonary ventilation, produce an even more severe degree of hypoxaemia. For reasons of safety, patients who appeared to have large quantities of mucus or mucopus in their bronchi were excluded from the present study, and this potentially dangerous effect of papaveretum could not therefore be investigated. Our observations make it clear that, even where this additional hazard may not be important, the administration of opiates to patients with chronic respiratory failure, particularly if the $\mathrm{PaCO}_{2}$ is above $60 \mathrm{~mm}$. $\mathrm{Hg}$, is likely to cause a significant and potentially deleterious reduction in $\mathrm{SaO}_{2}$. Although the administration of opiates may temporarily relieve the ' mental distress associated with severe dyspnoea, it does so only at the expense of a sharp increase in the degree of hypoxaemia, which in patients with ventilatory failure may have serious or perhaps even fatal consequences.

Only three patients were given papaveretum plus scopolamine, and it would not be justifiable to draw any conclusions from the results obtained in such a small series. However, the reduction in $\dot{V} E$ in two of the three patients was greater than in any of the 21 patients in whom VE was recorded before and after papaveretum alone. Although in both these patients there was a corresponding rise in $\mathrm{PaCO}_{2}$ and a fall in $\mathrm{SaO}_{2}$, neither of these changes was commensurate with the degree of reduction in $\dot{V}$. All three patients became very drowsy after the drugs had been given, and this may conceivably have introduced an error into the second recording of VE. It is possible that the simultaneous administration of scopolamine accentuated the respiratory depressant effect of papaveretum. This impression differs from the conclusions of Wangeman and Hawk (1942), who in normal subjects found that the depression of minute volume by morphine was counteracted by scopolamine. It may be that the effect of these drugs on respiration in patients with chronic bronchitis differs from their effect on normal subjects. This is a point which may be of practical importance when premedication is prescribed for patients with chronic respiratory disease and one which deserves further study.

\section{SUMMARY}

The effect of opiates on patients with chronic bronchitis was studied before and 60 minutes after a subcutaneous injection of papaveretum $(20 \mathrm{mg}$.) by measuring arterial oxygen saturation $\left(\mathrm{SaO}_{2}\right)$, carbon dioxide tension $\left(\mathrm{PaCO}_{2}\right), p \mathrm{H}$, plasma bicarbonate, and the minute volume of pulmonary ventilation ( $\dot{V} E)$.

Twenty-four studies were performed on 22 patients. Before the injection was given the $\mathrm{PaCO}_{2}$ was below the accepted upper limit of normal $(47 \mathrm{~mm}$. $\mathrm{Hg}$ ) in eight patients : in the other 16 , all with stabilized chronic ventilatory failure, the $\mathrm{PaCO}_{2}$ ranged between $47 \mathrm{~mm}$. $\mathrm{Hg}$ and $98 \mathrm{~mm}$. Hg. Except in two patients, the arterial $p H$ was normal, since it was not considered advisable to administer an opiate to patients with uncompensated respiratory acidosis.

The most common pattern of response to papaveretum was a reduction in $\dot{\mathrm{VE}}$ and $\mathrm{SaO}_{2}$, an increase in $\mathrm{PaCO}_{2}$, and a slight fall in $p \mathrm{H}$, which had not (after 60 minutes) been corrected by an increase in plasma bicarbonate.

The reduction in $\mathrm{SaO}_{2}$ was proportionately greater than the increase in $\mathrm{PaCO}_{2}$. The possible reasons for this are discussed.

The amount by which the $\mathrm{PaCO}_{2}$ increased after the injection of papaveretum did not appear to be related to the degree of ventilatory failure, but greater reductions in $\mathrm{SaO}_{2}$ were recorded in hypercapnic than in normocapnic subjects.

As hypoxaemia, often of a serious degree, is invariably present in hypercapnic patients, the 
administration of an opiate in such circumstances is liable to reduce the $\mathrm{SaO}_{2}$ to a dangerously low level. This observation, apart from the additional hazards which may arise from increased hypercapnia and from the antitussive effects of the drug, makes us think that opiates should not be given to patients with chronic ventilatory failure, even for the relief of severe dyspnoea.

Our thanks are due to Miss Thea Sanders and Miss Linda Tully for technical assistance, and to Miss Joyce Holywell for secretarial help.

This research programme has been supported by a grant from the Scottish Hospital Endowments Research Trust.
Byles, P. H. (1960). Observations on some continuously-acting spirometers. Brit. J. Anaesth., 32, 470.

Campbell, E. J. M. (1962). RIpH. Lancet, 2, 154.

Loeschcke, H. H., Sweel, A., Kough, R. H., and Lambertsen, C. J (1953). The effect of morphine and of meperidine (Dolantin Demerol) upon the respiratory response of normal men to low concentrations of carbon dioxide. J. Pharmacol. exp. Ther., 108 376.

Severinghaus, J. W., and Bradley, A. F. (1958). Electrodes for blood$p \mathrm{O}_{2}$ and $p \mathrm{CO}_{2}$ determination. J. appl. Physiol., 13, 515 .

Wangeman, C. P., and Hawk, M. H. (1942). The effects of morphine,atropine and scopolamine on human subjects. Anesthesiology, $3 \overrightarrow{-}$ 24.

Wilson, R. H., Hoseth, W., and Dempsey, M. E. (1954). Respiratory acidosis. I. Effects of decreasing respiratory minute volume in patients with severe chronic pulmonary emphysema, with specific reference to oxygen, morphine and barbiturates. Amer. J. Med., N $17,464$.

Zijlstra, W. G. (1953). Fundamentals and Applications of Clinical Oximetry, 2nd ed. Van Gorcum, Assen, Netherlands. 